\title{
In Situ Quantification of Degradation Is Needed for Reliable Risk Assessments and Site-Specific Monitored Natural Attenuation
}

\author{
Ottosen, Cecilie Bang; Murray, Alexandra Marie; Broholm, Mette Martina; Bjerg, Poul Løgstrup
}

Published in:

Environmental Science and Technology

Link to article, DOI:

10.1021/acs.est.8b06630

Publication date:

2019

Document Version

Peer reviewed version

Link back to DTU Orbit

Citation (APA):

Ottosen, C. B., Murray, A. M., Broholm, M. M., \& Bjerg, P. L. (2019). In Situ Quantification of Degradation Is Needed for Reliable Risk Assessments and Site-Specific Monitored Natural Attenuation. Environmental Science and Technology, 53(1), 1-3. https://doi.org/10.1021/acs.est.8b06630

\section{General rights}

Copyright and moral rights for the publications made accessible in the public portal are retained by the authors and/or other copyright owners and it is a condition of accessing publications that users recognise and abide by the legal requirements associated with these rights.

- Users may download and print one copy of any publication from the public portal for the purpose of private study or research.

- You may not further distribute the material or use it for any profit-making activity or commercial gain

- You may freely distribute the URL identifying the publication in the public portal 


\title{
In situ quantification of degradation is needed for reliable risk assessments and site-specific monitored natural attenuation
}

\author{
Cecilie B. Ottosen*, Alexandra M. Murray, Mette M. Broholm and Poul L. Bjerg
}

Corresponding author*ceot@env.dtu.dk

Contamination of soil and groundwater is a global problem, and clean-up can be an expensive and arduous task. Risk assessments are therefore required for prioritization and decision-making, and numerous risk assessment tools exist worldwide. Some contaminants can be degraded under field conditions without any human interference. Hence, to produce accurate risk assessments of soil and groundwater contamination, it is crucial to include degradation. As an example, if degradation is not included in the assessment for chlorinated ethenes the risk may be underestimated, as the degradation product vinyl chloride is more hazardous than its mother compounds. For petroleum hydrocarbon contamination, the down-gradient risk would be overestimated if degradation of the readily consumed toluene is ignored. Including degradation and the rate at which it progresses is thus essential for a full assessment of risk and informed prioritization of contaminated site clean-up.

Consequently, there is a need for field based degradation rates. Nonetheless, despite increasing knowledge about degradation characterization and the continuous development of new tools for documentation and quantification (Bombach et al., 2010), degradation rates are rarely quantified at the field scale. A literature search for relevant and dominant soil and groundwater contaminants shows that field based, first-order degradation rates are sparsely available (Ottosen et al., 2018). The literature search further revealed that the published rates range considerably. An example of this can be seen in Figure 1 for chlorinated aliphatic compounds, where the few rates that are available correspond to half-lives ranging from 0.4-2300 days. Most rates for common contaminants were published in the 1980s and 1990s 
when it was more challenging to determine degradation rates than it is today, with modern quantitative tools. In addition, many of the available rates are determined at the laboratory scale and are thus not directly comparable to the complex and heterogeneous conditions at the field scale. This stresses the importance of colleting numerous field based degradation rates for individual compounds to define realistic ranges for reliable risk assessments.

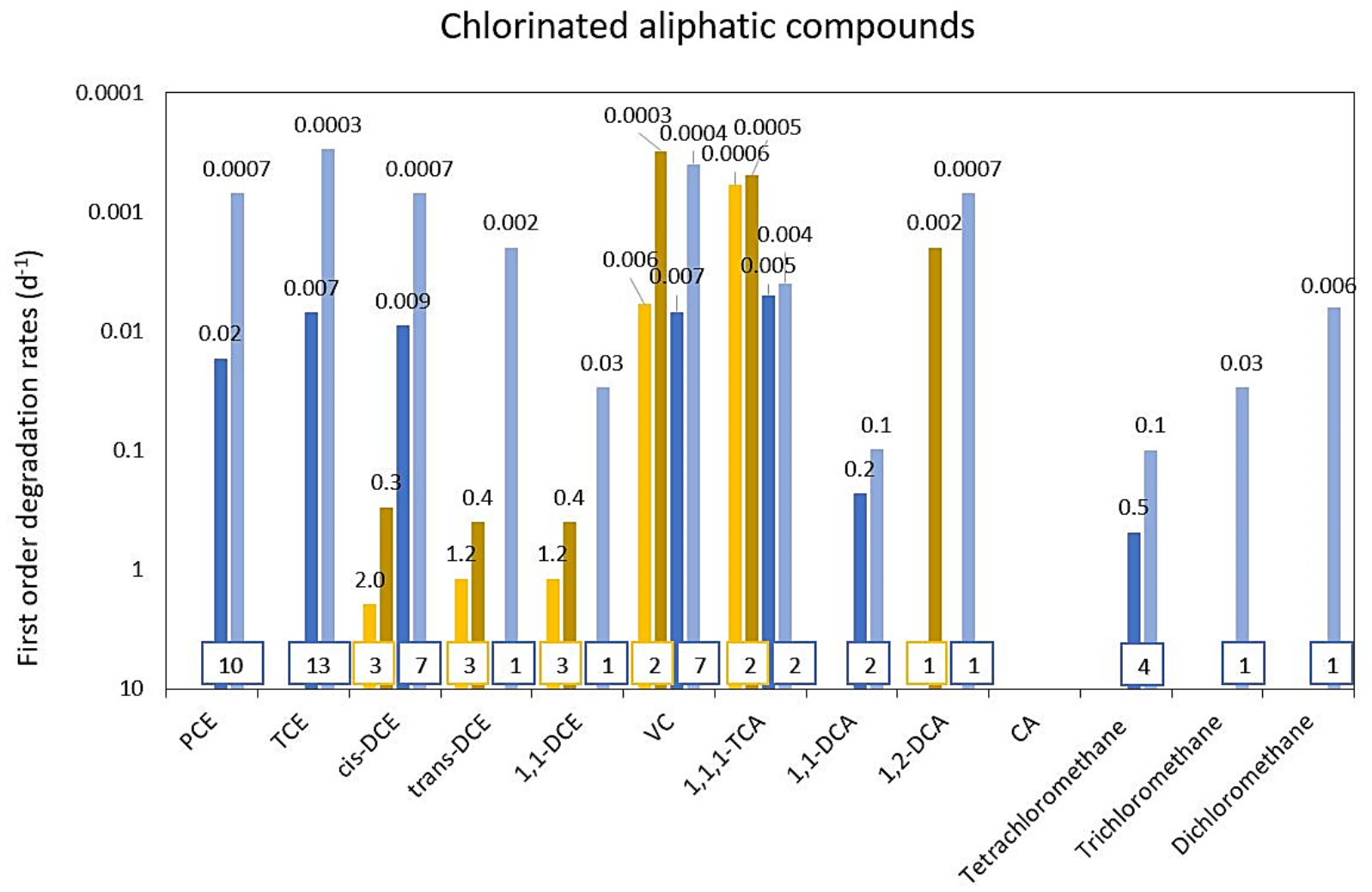

Figure 1: First-order degradation rates for chlorinated aliphatic compounds presented in the literature and summarized by Ottosen et al. (2018). The number of degradation rates collected for each compound and redox condition is defined at the base of the bars. Aerobic maximum, aerobic minimum, anaerobic maximum, anaerobic minimum.

Quantification of degradation is not only important for risk assessments but also at the site-specific scale for remedial actions. Under the right conditions, degradation can result in complete contaminant 
destruction; for this reason, Monitored Natural Attenuation (MNA) has been of interest for decades as a cost effective clean-up method. During MNA, a portion of the aquifer is allowed to act as a reactor and natural processes are relied upon to decrease contaminant concentrations to achieve remediation objectives. Monitoring in MNA is conducted with a multiple lines of evidence (MLE) approach, including lines such as direct measure of contaminant loss, indirect measure of degradation by geochemical and biological parameters, and quantitative measures like compound specific isotope analysis (Bombach et al., 2010). Comprehensive monitoring is crucial in MNA to evaluate degradation efficiency and to support the use of this specific remediation technique at site. The MLE approach has only been applied to a limited extent and only for selected compounds, and therefore additional field tests are required to build upon the library of conditions where the methods can successfully be applied.

A promising new technique to quantify degradation at the field scale is compound specific isotope analysis (CSIA). Chemical bonds with lighter isotopes are weaker than those with heavy isotopes, and bacteria preferentially degrade molecules that contain the weaker bonds. This means the ratio of light to heavy isotopes changes as degradation progresses and the enrichment of heavy isotopes indicates the extent of degradation. A major advantage of CSIA is that other physical processes (e.g. dilution and volatilization) that decrease contaminant concentrations typically have a minor effect on the isotope signatures, so it is possible to distinguish between destructive and non-destructive processes. By comparing different isotope signatures from different components of a single compound (e.g. carbon and chlorine for chlorinated ethenes), it is even possible to identify degradation pathways. Additionally, if the transportation time is known, the down-gradient degradation can be quantified. Nevertheless, due to uncertainty caused by the heterogeneity of aquifer systems, other lines of evidence should be used to support the assessment (Thullner et al., 2012; Morill et al. 2005).

Contaminant degradation in natural environments depends on several factors, including the groundwater aquifer microbial community's ability to degrade the contaminant. It is important to assess if the 
community's inherent degradation capability alone can achieve the desired results, or if bio-stimulation and -augmentation are needed. This ability can be evaluated via numerous molecular methods (Yargicoglu and Reddy, 2015), which vary in both the amount of information obtained and cost. The presence of specific, known species, genera, or functional genes can be assessed by polymerase chain reaction (PCR) at relatively low cost, while tools such as metagenomics yield information about the functional capacity of the entire community, not just known degraders, at a higher cost. Activity of known degraders, rather than just their presence or abundance, can be determined by analysis of messenger RNA. Non-molecular, experimental methods, such as laboratory/in-situ microcosms, can also be used to ascertain the community's degradation capability. However, standalone application of these molecular and nonmolecular microbial techniques is insufficient for determination of degradation rates or evaluation of MNA applicability, and microbial techniques are commonly used in combination with other lines of evidence (Yargicoglu and Reddy, 2015).

In conclusion, even though CSIA and microbial techniques are promising for site-specific documentation and quantification of degradation, an MLE approach is necessary, as no standalone method exists at the current knowledge level. Thus, application of these tools is required in various environments and plume complexities to better characterize and quantify the degradation of individual compounds and apply sitespecific MNA. Further, application of the tools will provide the field based degradation rates needed to determine realistic ranges that then ensure reliable risk assessments. As these methods become more robust and when the amount of data and knowledge increase, risk assessments, site-specific MNA applications, and site clean-up prioritization will become more accurate and reliable. 


\section{References}

Bombach, P., Richnow, H. H., Kästner, M. and Fischer, A. (2010). Current approaches for the assessment of in situ biodegradation. Applied Microbiology and Biotechnology, 86, pp. 839-852.

Morrill, P. L., Lacrampe-Couloume, G., Slater, G. F., Sleep, B. E., Edwards, E. A., McMaster, M. L., Major, D. W. and Lollar, B. S. (2005). Quantifying chlorinated ethene degradation during reductive dechlorination at Kelly AFB using stable carbon isotopes. Journal of Contaminant Hydrology, 76, pp. 279-293.

Ottosen, C. B., Bjerg, P. L., Broholm, M. M. and Søndergaard, G. L. (2018). Degradation rates for application in GrundRisk risk assessment - Literature study [Danish]. Environmental Project nr. 2013. Danish Environmental Protection Agency. Copenhagen, Denmark. Link: https://www2.mst.dk/Udgiv/publikationer/2018/05/978-87-93710-15-3.pdf

Thullner, M., Centler, F., Richnow, H. H. and Fischer, A. (2012). Quantification of organic pollutant degradation in contaminated aquifers using compound specific stable isotope analysis - Review of recent developments. Organic Geochemistry, 42, pp. 1440-1460.

Yargicoglu, E. N. and Reddy, K. R. (2015). Review of biological diagnostic tools and their applications in geoenvironmental engineering. Reviews in Environmental Science and Biotechnology, 14, pp. 161-194. 